\title{
A DIMENSÃO SOCIOESPACIAL DO CONHECIMENTO COMO TRAÇO EXISTENCIAL DO HOMEM E DE SEU TERRITÓRIO
}

\author{
DIMENSIÓN SOCIO-ESPACIAL DEL CONOCIMIENTO \\ COMO UNA MARCA EXISTENCIAL DEL HOMBRE Y SU \\ TERRITORIO
}

\begin{abstract}
Lucileide Andrade de Lima do Nascimento - lucileidelima@gmail.com Doutoranda pelo Programa de Doutorado Interinstitucional em Ciência da Informação UFES-UnB (DINTER UFES-UnB) - oferecido pela Universidade de Brasília (UnB). Professora do Departamento de Biblioteconomia da Universidade Federal do Espírito Santo (UFES).

Emir José Suaiden - emir@unb.br Doutor em Ciência da Informação pelo Universidad Complutense de Madrid, Espanha.Professor da Faculdade de Ciência da Informação da Universidade de Brasília (UnB).
\end{abstract}

\section{RESUMO}

Introdução: Analisa a informação como uma dimensão determinante no processo de reprodução social, portanto, um fenômeno que não pode ser desprezado na análise da sociedade.

Objetivo: Situar o uso da informação e do conhecimento como uma prática social e eminentemente coletiva, que se estabelece na relação entre sujeitos e entre o sujeito e 0 seu meio (território), com base no paradigma social da informação.

Metodologia: Desenvolve a partir de pesquisa bibliográfica articulação teórica, sob uma abordagem interdisciplinar, tratando do lugar da informação e do conhecimento na sociedade e da relação entre as categorias controle social e controle social da informação como mecanismo social para a efetivação da governança informacional sob um regime de informação, para atendimento da necessidade comunicacional e informacional da sociedade. 
Conclusões: A categoria controle social aplicada ao campo da informação (controle social da informação) se apresenta como um mecanismo estratégico para: viabilizar a efetiva gestão e socialização da informação local fundada no direito a informação; e viabilizar canais de participação da sociedade civil sob um regime de informação e promotor de processos de governança informacional.

Palavras-chave: Informação e sociedade. Socialização do conhecimento. Território e informação. Controle social e informação.

\section{INTRODUÇÃO}

A articulação teórica desenvolvida trata do lugar da informação e do conhecimento na sociedade. A informação e o conhecimento podem ser definidos, primeiramente, como produtos sociais oriundos das práticas discursivas, estabelecidas nos modos de ser e nas relações sociais que os sujeitos são capazes de estabelecer. Logan (2012) descreve que a informação influencia de forma direta a condição humana em quatro grandes esferas: a biosfera (organismos vivos), a simbolosfera (linguagem e cultura), a tecnosfera (tecnologias) e a econosfera (organizações econômicas e governamentais).

A perspectiva da informação como valor social se constitui também como uma das vertentes teóricas pesquisadas no âmbito da Ciência da Informação. Os estudos em Ciência da Informação, de modo sintético, perpassam três paradigmas: o paradigma cognitivo focaliza os processos de organização e tratamento da informação, a partir de uma abordagem centrada no indivíduo; o paradigma físico está direcionado também para a organização e tratamento da informação, mas, numa perspectiva sistêmica, fundada nos processos tecnológicos; e por último, $\mathbf{0}$ paradigma social, denominado por Hjørland (2000) como uma abordagem centrada nos processos sociais e culturais, objetiva a análise da informação socialmente construída.

No paradigma social, a informação se apresenta como um fenômeno histórico, social, cultural e da humanidade. A ancoragem teórica busca construir princípios que aperfeiçoem as práticas sociais de natureza informativa. Nesse 
sentido, entendemos que a produção, a socialização e o uso de conhecimento ${ }^{1}$ e informação $^{2}$ se estabelecem como processos socioculturais, cujas práticas e relações são evidenciadas em suas dimensões espacial/territorial e temporal/histórica (ALBAGLI; MACIEL, 2004). A informação "[...] é essencialmente relacional, não podendo ser avaliada ou sequer percebida, fora de um contexto social." (SILVEIRA, 2000, p. 87).

\section{A INFORMAÇÃO COMO FENÔMENO SOCIAL}

Marteleto (apud ANDRADE; RIBEIRO, 2003) observa que a compreensão da informação como um fenômeno social e como um processo comunicacional ${ }^{3}$ humano exige: sua contextualização (cidade), meios de representação (a biblioteca, o museu, o centro cultural), compartilhamento de significados (sentido), capacitação em informação (especialistas), inteligência social (projeto, redes e tecnologias) e outros elementos afeitos à compreensão e interpretação da informação (GLEICK, 2013; LOGAN, 2012).

O conceito de conhecimento impõe uma delimitação espacial e temporal, exigindo um contexto econômico e sociocultural específico e sempre diferenciado: o conhecimento das pessoas (sujeitos individuais), das organizações públicas e privadas (grupos sociais), das comunidades, das populações, da indústria, etc. No paradigma social, o conhecimento é formado por esses campos coletivos de conhecimento (sujeitos, grupos sociais, organizações, dentre outros) ou domínios referentes às suas comunidades discursivas (LOGAN, 2012).

\footnotetext{
${ }^{1} \mathrm{O}$ conhecimento é um elemento que media a ação racional dos sujeitos nas relações sociais (ANDRADE; RIBEIRO, 2003). O conhecimento é "[...] a aplicação e o uso produtivo da informação" (ROBREDO, 2003, p. 16), ele "[...] emerge de uma situação social, no espaço social [...]" por isso mesmo "[...] todo conhecimento é social e está historicamente condicionado." (ANDRADE; RIBEIRO, 2003, p. 10-11).

${ }^{2}$ Informação aqui é entendida como conhecimento para a ação (uma concepção antropológica), o conhecimento esclarece que a ação é racional (ANDRADE; RIBEIRO, 2003). A informação pode ser compreendida como um dado, situado em um contexto, que foi organizado de forma significativa (ROBREDO, 2003, p.16), como um "[...] processo de elaboração de sentido sobre as coisas e os sujeitos no mundo [...]." (ANDRADE; RIBEIRO, 2003, p. 10).

${ }^{3} \mathrm{O}$ processo comunicacional age sobre o fenômeno informacional: "[...] não há comunicação sem informação, mas pode haver informação sem comunicação." (SILVA; RIBEIRO, 2002, p. 26).
} 


\begin{abstract}
Estas comunidades não são entidades autônomas, mas distintas construções sociais compreendidas por indivíduos sincronizados em pensamento, linguagem e conhecimento, e constituintes da sociedade moderna. Naturalmente, concatenadas às dimensões culturais e sociais (NASCIMENTO, 2006, p.29).
\end{abstract}

"A informação possibilita a existência de "cada ser - cada partícula, cada campo de força, até o próprio continuum espaço-tempo." (GLEICK, 2013, p. 18).

O uso social da informação insere e constitui o sujeito coletivo (cidadão): "Nós geramos, nós disseminamos, nós usamos [...]". E é este sujeito-coletivo que qualifica o seu processo de participação e o controle (social) sobre o Estado (GONZÁLEZ DE GÓMEZ apud ANDRADE; RIBEIRO, 2003, p. 14). A informação encontra-se ligada (e mediando) à produção de conhecimento pelo sujeito e pelo seu grupo (BARRETO, 1994). "O homem porém precisa da informação sobre os outros porque é sobre esta noção que funda sua relação com eles." (PINTO, 2005, v. 2, p. 244).

Cada local e cada região constitui o seu bem coletivo (físico, social, cultural, político, etc.), a sua herança cultural, que diretamente influenciam a forma de aprender e construir conhecimento. A resultante dessas combinações e/ou interações, em determinado espaço, apresenta-se como um conhecimento coletivo de natureza diferenciada e desigual em sua distribuição: podendo constituir-se como "[...] fonte de dinamismo [...]" ou fonte de agravamento das desigualdades sociais (ALBAGLI; MACIEL, 2004, p. 11).

\title{
3 AS PRÁTICAS DE NATUREZA INFORMATIVA
}

A prática social, de natureza informativa, estrutura-se através do processo de geração e transferência de informação envolvendo ações de atribuição de sentido. Se não acontecer a atribuição de sentido durante 0 ato de recepção da informação, o processo de representação (geração e transferência) da informação não se desenvolve. Isto explica porque, em certos contextos, as oportunidades de transformação, a partir da atribuição de sentidos, são manipuladas e podem não ocorrer.

A atribuição de sentido remete ao papel do receptor, exige estrutura mental, social e cultural adequada. Um livro, para desencadear a atribuição de sentido, exige: a capacidade de ler, o conhecimento do idioma, a partilha da forma de vida ou 
das referências sociais e culturais em que a mensagem (ou conteúdo da obra) está inserida.

Essa atribuição de sentido é desencadeada na forma de socialização da informação, em que um quadro de referências comuns (entre o receptor e a mensagem) precisa ser construído, levando em conta o conhecimento pessoal ou tácito desse receptor: os seus modelos mentais, esquemas, paradigmas, perspectivas, crenças e pontos de vista, sob os quais esse sujeito percebe e define o seu mundo (OLIVEIRA, 2005). Assim, quanto: "[...] menor for o acervo social do conhecimento desse sujeito menos apto ele se sente para entender determinada informação e conseqüentemente, mais propício estará a seguir o caminho traçado pelo sujeito emissor." (ARAÚJO, 2001, p. 5).

Segundo Berger e Luckmann (2002) o conhecimento coletivo, oriundo das práticas sociais, advém do sujeito social: do seu acervo social do conhecimento, como produto das soluções construídas para enfrentamento dos problemas. Esse chamado acervo social do conhecimento contempla o conhecimento de si (situação, objetivos e necessidades) e o conjunto de seus limites, de acordo com a capacidade de construção social da sua realidade.

Configura-se, por consequência, como um processo cíclico, repetido para todo o conjunto de informações que regularmente recebe para viver. Nessa relação com o seu acervo social de conhecimento, busca um sentido para as informações recebidas, selecionando aquela passível de ser utilizada: tem-se nesse momento, o homem como ser consciente, que reflete e assume a posição de assimilação da informação, "[...] um ponto de consciência cognitiva [...]" (ARENDT, 1991 apud BARRETO, 1999). Um sujeito cognitivo-social que atribui sentido à informação em um "[...] contexto que é composto pela sociabilidade (experiência coletiva) e pela atividade cognitiva do sujeito" (ARAÚJO, 2001, p.4).

A assimilação pressupõe que a informação recebida foi capaz de produzir transformações no estado mental do sujeito social, pois uma vez selecionada e assimilada conduz a uma mudança de um estado de conhecimento para outro (pela redução de graus de incerteza); por efeito, esse novo conhecimento, uma vez socializado, pode também provocar transformações nos contextos, de forma espontânea (nas relações sociais entre os sujeitos) ou provocada (pelo estímulo da mídia, por exemplo). 
O processo de assimilação é a forma de interação entre o sujeito e a estrutura de informação, que "[...] gera uma modificação em seu estado cognitivo [...]" (BARRETO, 1998, p. 69), produzindo assim, um tipo de conhecimento relacionado com a informação recebida. A informação, enquanto fato social opera como estrutura significante para provocar conhecimento nos sujeitos e em seus coletivos. O desenvolvimento desses sujeitos é "[...] decorrência social natural da acumulação deste conhecimento" (BARRETO, 1998, p.69). Como fato cognitivo do sujeito, sua natureza e função conservam um elemento de sentido (BARRETO, 1998; CASTRO, 2002).

O sujeito social (BERGER; LUCKMANN, 2002), só produz conhecimento ao utilizar a informação (com sentido) para resolver determinado problema. A informação enquanto prática social envolve ações de atribuição e comunicação de sentido, a partir dos critérios de seleção que esse sujeito utiliza, no ato da recepção da informação, para decidir sobre o uso ou não da informação acessada. Ele recebe a informação e em seguida desenvolve uma ação propositiva, uma ação que salienta sua postura ou intenção sobre essa informação acessada. A informação acessada/consumida é transformada em informação selecionada/útil, quando ocorre: uma inter-relação entre a informação recebida e a realidade vivida pelo sujeito; e uma "[...] compreensão do código utilizado para o envio da informação [...]" (ARAÚJO, 2001, p. 4), devendo existir um referencial comum para que os dados desencadeiem informação (OLIVEIRA, 2005).

Segundo Berger e Luckmann (2002) em nossa vida cotidiana surgem questões que podem ou não ser consideradas problemáticas. A ação de enfrentamento das dificuldades é enriquecedora, trazendo novos conhecimentos, oriundos das soluções que criamos para resolver problemas. O conhecimento produzido no enfrentamento do problema passa a integrar nosso acervo social de conhecimento, por isso mesmo podemos dizer que a informação que chega ao sujeito atua como um redutor de incertezas, propiciando um conhecimento que gera oportunidades de mudanças ou transformações.

Esse processo se repete indefinidamente, ou seja, para todas as informações recebidas, o indivíduo busca um sentido no seu acervo social de conhecimentos e, uma vez atribuído tal sentido a informação pode ser utilizada ou não. Isso vai depender da informação recebida, da realidade/situação que está sendo 
vivenciada pelo sujeito e do sentido que ele mesmo atribui a esta informação (ARAÚJO, 2001, p. 5).

Em linhas gerais, todo conhecimento é social e historicamente condicionado, está na essência das demandas da vida humana e depende da articulação coletiva. É produto de classes sociais, representativa dos interesses, dependendo da posição que ocupa junto ao processo produtivo (ANDRADE; RIBEIRO, 2003; ARAÚJO, 1992). A informação é a matéria-prima e o produto (com duplo caráter), que perpassa todos os momentos do processo de construção do conhecimento (ARAÚJO, 1992).

A cultura, segundo Marteleto (1995), é depositária da informação social, tanto para conservar como para reproduzir a memória da experiência humana. $\mathrm{Na}$ construção conceitual, a informação é o artefato simbólico e material e o processo que alimenta os modos de ser, estar, representar em sociedade. Assim, quando se discute a socialização do conhecimento, preserva-se as possibilidades de universalização do acesso e de uso da informação (transformada em conhecimento) como um bem simbólico universal.

É nesse sentido que compreendemos também o direito a informação, um recurso simbólico que reproduz e representa a informação como um mediador das relações sociais de natureza informativa. A aplicação desse direito pelo Estado se expressa pelas políticas públicas ligadas à comunicação e à informação, promovendo a oportunidade de transformação desse sujeito social através da ampliação e qualificação do seu acervo social de conhecimento, propiciando acesso universal e mais igualitário ao conhecimento, mediado por redes informacionais contextualizadas. Pela via redistributiva, a informação deve fundar-se na igualdade e universalidade sendo fator contributivo para a democratização dessa sociedade.

Por isso podemos dizer que a informação socialmente produzida tem a potencialidade de transformar o meio e o sujeito, como também se apresentar como recurso para enfrentamento da desigualdade - tratamos então de uso da informação para fins sociais (ARAÚJO, 2001).

Ao longo de sua história, o conhecimento tem sofrido distinções relacionadas à sua objetividade e forma de circulação. O conhecimento tácito (ou do senso comum), científico e tecnológico. Em si, constituem um legado social, que em seu antagonismo tem sido fortemente conduzido para um processo de ampla produção, 
mas também de reduzida socialização. São resultantes de fortes tensões entre os que advogam que o conhecimento é um bem público, portanto, facultado a toda sociedade e de outro lado, os que detêm as tecnologias de informação e comunicação, defendendo o seu uso para fins econômicos, ligados aos interesses capitalistas. Como exemplo, temos a informação tecnológica, principalmente fomentada pela indústria (GENTILLI, 2005; LASTRES; AUN, 1997; QUÉAU, 2001).

Chegamos aqui a um ponto crucial: a informação pode instituir e redesenhar relações de poder ${ }^{4}$, controle e domínio sobre os sujeitos, organizações e nações. "A posse de informações sempre foi elemento determinante do poder [...]" (SILVEIRA, 2000, p. 85). O domínio e controle estratégico de informações por grupos econômicos e de poder têm determinado polarizações e impedido a socialização do conhecimento para benefício social (LASTRES; AUN, 1997). A desigualdade entre sociedades "[...] expressa hoje fundamentalmente a desigual distribuição socioespacial de conhecimentos e informações estratégicas." (LASTRES; ALBAGLI, 1999, p. 310; SUAIDEN; LEITE, 2006).

A dinâmica de mercado, no contexto atual, orientada pela globalização e economia global, favorece a manutenção das desigualdades entre os países, principalmente tratando-se de ciência e de tecnologia, representando um processo sempre desigual de "[...] transformação de dados em informação, de informação em conhecimento, de conhecimento em inteligência social." (JARDIM, 1999, p.29).

Observa-se que, tanto a informação como o Estado se apresentam como fenômenos históricos de apropriação e controle monopolista do capital, como recurso estratégico para o alcance dos superlucros e manutenção da cultura capitalista. Esse nexo, a principio, permite explicar a problemática que envolve a institucionalização de processos democráticos e de favorecimento de controle, pelo Estado, dos mecanismos de comunicação e de informação (seja governamental ou aquele socialmente produzido pela ciência). Há forte defesa para manutenção do

\footnotetext{
${ }^{4}$ Nos apropriamos da compreensão de poder discutida por Silveira (2000, p. 80) que assim o define: "[...] um fenômeno social no qual uma vontade, individual ou coletiva, se manifesta com capacidade de estabelecer uma relação da qual resulta a produção de efeitos desejados, que de outra maneira não ocorreriam espontaneamente". Toffler (apud SILVEIRA, 2000, p. 80) complementa que "[...] o poder tem como fontes básicas o 'músculo' (força), o 'dinheiro' (riqueza) e a inteligência' (conhecimento) com esta última apontada como a fonte de maior qualidade, pela possibilidade de incrementar a aplicação de outras fontes".
} 
monopólio privado, mesmo em se tratando de concessões, como é o caso das telecomunicações no país.

O novo padrão tecnológico fomentado pelo mercado, expressa uma relação cooperativa entre tecnologia, informação e comunicação; possui um potencial integrativo, porém precisa ser usado em favor do interesse público (junto à sociedade civil) - propiciando ao poder local a densidade comunicacional, informacional e técnica no ambiente de redes informacionais (LASTRES; ALBAGLI, 1999) e na publicização das informações de natureza pública (sejam administrativas, técnicas, cientificas e/ou ligadas à cultura). Andam em proximidade os processos sociais que criam e manipulam os artefatos simbólicos (a cultura) e a própria capacidade de produzir e distribuir bens e serviços (pelas forças produtivas): uma relação entre processos culturais e processos produtivos (CASTELLS, 2002).

\section{TERRITÓRIO, PODER LOCAL E INFORMAÇÃO}

O cenário mundial vivencia um processo de transformação da economia sem precedentes, com mudanças marcantes nos fluxos de comércio, no peso relativo das economias centrais e no plano político, com a imposição de desafios para os países emergentes, incluindo o Brasil.

Essa realidade social aponta para uma base tecnoprodutiva intensiva em conhecimento como matriz mediadora da dinâmica de reprodução social. A sua natureza, eminentemente tecnológica e econômica, caracteriza a intensidade com que as mudanças ocorrem e a urgência no desenho de políticas e práticas de gestão das oportunidades e desafios que se colocam relativos à centralidade do conhecimento na condução dos processos em diferentes dimensões da vida em sociedade. Uma sociedade orientada ao uso intensivo de conhecimento desencadeia simultaneamente fenômenos de maior igualdade e desigualdade, de homogeneidade e de diferenciação nos processos de disseminação da informação produzida (SUAIDEN; LEITE, 2006).

Especificamente poderíamos tratar das dimensões espaciais e socioinstitucionais da produção, difusão e uso de conhecimento para melhor contextualizar essa realidade que designa um papel estratégico para a informação. Considerando a temática informação nos interessa pensar que o protagonismo local está diretamente relacionado às condições de reconhecimento, apropriação e gestão 
dos saberes locais. Políticas de enfoque territorial, valorizando a dimensão local, também vêm sendo adotadas em boa parte da América Latina por recomendação de agências multilaterais, em geral de orientação neoliberal. Esta discussão remete a outra problemática mais ampla e residual: os limites entre o Estado e o mercado, uma temática polêmica desde Adam Smith, com a mão invisível, e a existência de bens públicos contrapostos aos bens privados (ORTEGA, 2008).

Podemos orientar a discussão remontando o contexto dos debates ocorridos sobre as políticas públicas no Brasil, especificamente ao final da década de 1970, período identificado por uma importante inflexão contra o padrão centralizador, autoritário e excludente que historicamente marcou a relação entre as agências estatais e os beneficiários das políticas públicas, de questionamentos sobre a capacidade do Estado em responder as demandas sociais e a favor da necessidade de democratização dos processos. Na década seguinte essa inflexão encontrou sua formatação legal na Constituição de 1988, que sob as bases de um novo arranjo federativo, instituiu a descentralização e a participação social como princípios orientadores das ações, principalmente, nas áreas de saúde, previdência e assistência social (TATAGIBA, 2003). A relevância da descentralização reside no alcance de uma maior participação da esfera municipal no provimento de bens e serviços públicos.

Diversas ações de apoio a atividades produtivas e de desenvolvimento rural com enfoque territorial têm sido deflagradas por agentes de fomento e políticas de âmbito federal (ORTEGA, 2008). Tais estratégias foram apoiadas ou respaldadas por movimentos sociais locais que tinham como reinvindicação a maior participação em processos de formulação e gestão de políticas públicas. Estas reinvindicações não são novas, emergiram de experiências ainda na década de 1980, na busca de respostas efetivamente autônomas de desenvolvimento para resolver problemas instanciados nos espaços locais. A participação da sociedade civil foi marcadamente inscrita na Constituição de 1988 quando registrou como interesse social, a proposta de descentralização da administração pública ampliando respectivamente, o nível de responsabilidade das administrações estaduais e municipais com possibilidades de transferência de poderes decisórios a estados, municípios e depois sujeitos ou autores locais. Para auxiliar o processo de gestão pública foram criados os chamados arranjos sociais locais ou conselhos (consultivos ou deliberativos). Estes 
conselhos surgiram conceitualmente como "[...] espaços de concertação para construção de projetos locais com vistas ao desenvolvimento." (ORTEGA, 2008, p. $4)$.

Ao inicio da década de 1990, políticas neoliberais resultantes do Consenso de Washington passaram a ser implementadas para viabilizar o processo de desregulamentação da economia e de redução da participação do Estado no mercado. Nesse contexto convergiram interesses emergentes da sociedade civil organizada, de fortalecimento do espaço local como estratégia de enfrentamento das políticas multilaterais e de modelo Top down, e das instituições com prévia orientação neoliberal. Assim, ações e orientações oriundas de agências multilaterais e de governos foram ao encontro, segundo Ortega (2008), dos interesses e evocações dos defensores do poder local, que desejavam manter à distância das decisões locais, os governos autoritários. O que ocorreu foi uma mistura de discussões à volta do papel do Estado - criando segundo Ortega $(2008$, p. 15) "[...] um aparente Consenso em torno do tema do desenvolvimento local, uma vez que ambos - agências multilaterais e militantes localistas - defendem a possibilidade de construção de um modelo de desenvolvimento local autônomo e endógeno."

Analiticamente estas políticas de descentralização dos processos de tomada de decisão pelo Estado se apresentam funcionais tanto ao mercado quanto à sociedade civil. Sob a ótica do mercado significam o aprofundamento das ações do livre mercado também nos diversos níveis locais (de prerrogativa neoliberal): territórios sem a intervenção do estado central poderiam exercer "[...] suas vantagens comparativas para inserirem-se nos mercados globais" (CORAGGIO apud ORTEGA, 2008, p. 15). Sob a ótica da sociedade civil, processos de descentralização propiciam a iniciativa de atores e a emergência de protagonismos locais como enfrentamento aos sistemas globais que conduzem à perda de identidade das comunidades.

Sobre o aparente consenso quanto às estratégias promotoras do desenvolvimento social cabe observar que as transferências de responsabilidades designadas pela Constituição de 1988, nos três níveis da federação, não foram acompanhados de meios efetivos para o seu cumprimento. Ou seja, os recursos orçamentários e a distribuição de poderes para tomada de decisão não foram descentralizados. O que se percebe é que as distribuições assimétricas de recursos 
redundam também em assimetrias de poder de informação: os recursos oriundos da descentralização são captados justamente por regiões e localidades mais desenvolvidas ampliando assim, os níveis de desigualdades e disparidades entre as regiões.

Segundo Ortega (2008) esses territórios economicamente fragilizados são objetivamente, territórios deprimidos, constituídos por municípios com baixo nível de desenvolvimento e de crescimento. Apresentam indicadores abaixo da média nacional e uma capacidade institucional também aquém da média nacional de promover a participação na gestão local, gerencial e financeira. Sinteticamente, essas assimetrias são predominantemente relacionadas ao poder econômico, político e social. A assimetria de informação diante desse contexto se apresenta como um fenômeno fragilizador desses territórios deprimidos porque não ocorre um processo de distribuição ou partilhamento com equidade.

A literatura em Ciência da Informação sinaliza sobre a existência de lacunas quanto ao desenvolvimento de pesquisas e instrumentos facilitadores que propiciem o reconhecimento, e que "[...] demonstrem empiricamente a relevância dos fluxos locais de conhecimento [...]" (ALBAGLI; MACIEL, 2004, p. 9), ou ainda, do delineamento de fatores que podem interferir nestes fluxos de produção e compartilhamento de informações. Em tempos de globalização, mais ainda salientam-se as necessidades de situar os acontecimentos e processos (culturais, organizacionais, produtivos e políticos) em diferentes planos de integração (FREIRE, 2006) se considerarmos as complexidades que entrelaçam o local e as ocorrências de natureza global determinadas também pela questão da informação.

Cada local dispõe de diferentes combinações, dinâmicas, características e bens coletivos que por natureza influenciam a sua condição de produção/compartilhamento de informação. $O$ estudo das condições de produção e enunciação e de recepção e uso (de informação) envolve contextos diferenciados e por seguinte processos de territorialização (ou desterritorialização) da informação (GONZÁLEZ DE GOMEZ, 1996, 2000).

Entendemos que a noção de espaço local não é unívoca, se pensarmos uma sociedade multicultural poderíamos compreendê-la deste modo como convertendose em um fenômeno também multicultural (GARCÍA GOMÉZ; DÍAZ GRAU, 2006; PEDRO, 2011). Neste sentido a ideia de saber local se apresenta mais repleta de 
sentido quando reconhecemos que o conhecimento de uma determinada cidade não é universal, mas legitimamente remete às formas sociais de saberes locais (PEDRO, 2011).

\section{$5 \quad$ FLUXOS DE INFORMAÇÃO NA DINÂMICA TERRITORIAL}

Em se tratando de uma sociedade globalizada, a questão informacional impõe aos seus profissionais, ou aos atores sociais que lidam com informação, um efetivo controle sobre os fluxos de informação em todos os diferentes planos de integração: "Isto significa não somente promover o acesso a redes de informação globais para atores locais, mas também estabelecer conexões entre os espaços locais e globais [...]" (FREIRE, 2006, p.59). Sob a perspectiva de emancipação dos sujeitos de direitos, essas conexões devem contemplar dois tipos de procedimentos: o extrativo e o produtivo. No procedimento extrativo, os sujeitos se apropriam das informações circulantes nas redes e no procedimento produtivo, os sujeitos são ativos, se manifestam e se apresentam com "[...] presença argumentativa, econômica e política nos espaços das redes globais." (FREIRE, 2006, p. 59).

Castells (2002) e Jardim (2000) tratando das transformações do Estado sob influência da revolução informacional designa um modo de desenvolvimento informacional para esse Estado na localidade com potencial para a emergência de fluxos informacionais bidirecionais, permitindo um controle efetivo da sociedade civil sustentado por princípios democráticos (com maior sensibilidade às demandas dos sujeitos, maior autonomia para as políticas públicas e com maior condição institucional para absorver as técnicas e tecnologias voltadas para a gestão da informação) para implementação de políticas e mecanismos estruturais dirigidos à prevenção e diminuição da exclusão social e digital.

A governança informacional, sob um regime de informação, representa uma forma exequível desse desenvolvimento comunicacional-informacional do Estado (GONZALEZ DE GOMEZ, 1986; 2000). O poder local, sob um processo de governança informacional, pode propiciar mecanismos sociais de informação e de monitoramento das ações e decisões de interesse para o conjunto da sociedade. $A$ participação é um instrumento de controle do Estado pela sociedade, culminando no controle social e político - controle público do poder instituído. A participação e suas 
formas de manifestação não podem prescindir das garantias quanto ao direito de ser informado, da liberdade de expressão, da diversidade de fontes de informação, do direito de acesso a informações produzidas pelo Estado para propiciar a autonomia do sujeito de direitos. O controle social da informação ${ }^{5}$ como mecanismo de participação dos sujeitos de direitos define a natureza e interesses em jogo para a gestão do conhecimento local.

Realizamos a aplicação teórica da categoria controle social ao contexto do direito à informação. A categoria controle social tem sido apropriada pela sociedade civil para a gestão dos direitos sociais (principalmente junto aos Conselhos Gestores) e na função mediadora com a qual tem sido instrumentalizada, por ambas as partes, nas relações entre Estado e sociedade civil. Essa categoria propicia uma forma de efetivação do direito à informação, via controle social da informação, servindo para a própria legitimação do direito à informação junto à sociedade e para fortalecimento da descentralização participativa, emancipadora da dinâmica de participação social numa democracia.

A categoria controle social aplicada às questões de informação nos parece uma possibilidade de participação criativa e necessária aos ambientes da vida pública que se dedicam à comunicação e à informação. O caminho teórico procurou conjugar as ações estatais com as iniciativas, a participação e a capacidade decisória da sociedade civil na gestão das políticas públicas de informação conduzindo para o espaço público, a discussão e a representatividade social, por exemplo, das instituições que operam no local como o arquivo, a biblioteca e o museu, definindo a questão informacional como elemento de controle e tomada de decisão pela sociedade civil junto ao Estado. Do ponto de vista histórico, no caso específico dos arquivos e bibliotecas, a presença e participação da sociedade civil tem sido incipiente e de pouca efetividade.

O controle social da informação poder ser implementado como um mecanismo social de controle, pela sociedade civil, com dupla característica: para viabilizar a efetiva gestão e socialização da informação local fundada no direito a

\footnotetext{
${ }^{5}$ Esta expressão foi cunhada por Nascimento (2007) durante a produção da dissertação de mestrado sob a temática: Direito à informação e direitos sociais no contexto do capitalismo contemporâneo. A medida que o direito à informação se articula com os direitos sociais, a sua efetivação favorece a sociedade, propiciando as condições de controle social dessa informação, estabelecendo canais (comunicativo-informativos) e fortalecendo a dinâmica da participação (SILVEIRA, 2000). Atua como instrumento de poder para a expressão dos interesses, identidade, valores e como reforço à defesa da cidadania, amplia, dessa forma, as condições de resistência à mercantilização da informação.
}

Inf. Inf., Londrina, v. 20, n. 1, p. 01 - 25, jan./abr. 2015. http:www.uel.br/revistas/informacao/ 
informação; e viabilizar para os canais de participação da sociedade civil uma estrutura promotora da governança informacional em um regime de informação.

A necessidade informacional da sociedade civil deve constituir-se em uma demanda objetiva para o Estado. Este Estado, percebido como campo informativo, oferece um conjunto de possibilidades que se abrem para o exercício de um efetivo controle social da informação sobre si, pois as demandas informacionais não podem prescindir mais da existência de uma instância mediadora autônoma entre a sociedade civil e a sociedade política, ainda que os grupos de interesse sejam numerosos e tendentes à complexidade, torna-se indispensável um agente como canal de ligação, mediador/mediatizador para defender o uso deste recurso de poder: a informação social a ser apropriada pela sociedade civil e a favor do interesse público.

O mesmo se aplica à consolidação de políticas sociais, conforme identificado por Jardim (2000) indicando que em certos países em desenvolvimento a ausência de sistemas de informação compromete o processo político decisório.

Dar visibilidade à dimensão da informação social como necessidade/demanda social a ser tematizada, nos espaços e agendas públicas, significa incorporar à instrumentalidade da sociedade civil a dimensão informacional como recurso estratégico e de poder.

Se o fenômeno informacional tem uma dimensão global, ele também pode se manifestar na dimensão local, em espaços instituídos para dar visibilidade e garantir a participação dos sujeitos na construção de alternativas para tratar as demandas cobertas pelo direito a informação (TEIXEIRA, 2002).

O mecanismo de controle social da informação não pode limitar-se somente à criação de um papel de influência e decisório (o que não é pouco); ele deve apresentar-se como característico/próprio da esfera civil, como identidade da sociedade civil, sendo efetivo para a atividade de controle social e para consolidar os processos de democratização da própria sociedade civil. Deverá enfrentar duas dificuldades significativas e comuns aos espaços públicos: construir sua identidade (legitimada pela sociedade que representa) e constituir-se como um elemento de influência junto às relações entre Estado e mercado a favor do interesse público.

A reflexão prospectiva de uma nova forma de controle social da informação deve considerar que: a institucionalização dos conselhos gestores para exercício do 
controle social e da participação não está restrita a setores obrigatórios por força de lei federal, abrangendo antes, um conjunto significativo de áreas e temas demandados pela sociabilidade local, merecendo portanto, a sua institucionalização na forma da lei para as questões afeitas à informação.

Ainda que não haja restrições à sua institucionalização, a iniciativa por parte de atores advindos da sociedade civil para a criação de mecanismos de controle social garante maior legitimidade. É desejável e necessária a diversidade de segmentos sociais e de atores sociais em sua composição: instituições governamentais, movimentos sociais, instituições da sociedade civil, sindicatos, patronais. As condições de exercício da pluralidade precisam ser revistas para propiciar o acesso também de segmentos sociais com menor capacidade de organização e presença na vida pública.

A Lei de Acesso à Informação (LAl) em vigor no Brasil desde 2011 (Lei no 12.527, de 18 de novembro de 2011) representa no contexto de controle social da informação o dispositivo do Estado para universalizar o acesso à informação de natureza pública assegurando a gestão, acesso e divulgação de informações pelos órgãos e entidades do poder público, de instituições subsidiadas por recursos públicos ou de interesse público. Sua regulamentação pelo Decreto № 7. 724, de 16 de maio de 2012, de forma prática resgata, em certo nível, o processo histórico deflagrado pela Constituição de 1988, que na previsão legal do Art. 5ํ, inciso 33, trata das garantias de acesso a informação oriundas dos órgãos públicos pelo cidadão, seja para interesse particular ou coletivo (BRASIL, 2012).

Considerando o ambiente de governança informacional propiciado pelo Estado, tal esforço de regulamentação de práticas informativas e de disseminação sob a sua égide propiciarão à sociedade avançar no processo de controle e fiscalização das ações desenvolvidas pelos entes públicos. Quanto aos efeitos, desde a sua promulgação, já foram identificados e espera-se para todos os âmbitos das unidades federativas (federal, estadual e municipal) inicialmente a explicitação dos órgãos que ainda demandam procedimentos de organização de respectivos fluxos das informações produzidas para publicização e acesso, a identificação das estratégias de gestão da informação utilizadas pelos órgãos de governo e também, regular ações de gestores de cargos públicos quanto à imposição de interesses individuais sobre o interesse público ou coletivo (BRASIL, 2011; 2012). 


\section{CONSIDERAÇÕES FINAIS}

$\mathrm{Na}$ discussão tratamos de situar a informação e o conhecimento como uma prática social e eminentemente coletiva, que se estabelece na relação entre sujeitos e entre o sujeito e o seu meio, com base no paradigma social da informação.

Analisamos a informação como uma dimensão determinante no processo de reprodução social, portanto, um fenômeno que não pode ser desprezado na análise da sociedade. A vinculação da informação ao processo de reprodução social, a partir do sujeito social, estabeleceu o fundamento sobre o qual se define a noção de herança cultural e de bem público. Caracterizamos o sujeito produtor desse bem (quem produz) como um referente em relação ao qual o bem seria considerado público, a forma de produção (para a reprodução da vida) e a finalidade, como um fator essencial à sobrevivência e à autonomia do sujeito e da sociedade (o valor social da informação).

Essas conexões orientaram a vinculação entre informação, construção social do conhecimento e sujeito de direitos, ou seja, entre informação e sociedade (GONZÁLEZ DE GÓMEZ, 1986). Determinaram a via pela qual estabelecemos a noção de informação como um bem público, um valor que não pode ser apropriado e retirado do seu contexto para fins de acumulação, visto que perde o seu efeito social.

$\mathrm{Na}$ atualidade, a centralidade da informação como mercadoria tem definido a desigualdade, tanto na produção, quanto no monopólio de conhecimento. Uma distorção severa e comprometedora da reprodução social, que interrompe, manipula e deforma o ciclo de produção, geração e transferência da informação (despojando o sujeito de seu maior valor social e do instrumento garantidor de sua sobrevivência autônoma) um elemento desencadeador e no epicentro da desigualdade social. $\mathrm{Na}$ defesa dos bens públicos nos parece que o local define um território por excelência para a reconstrução de laços de pertencimento, solidariedade e da própria identidade coletiva como reação ao individualismo exacerbado, que define na atualidade as lógicas da convivência.

Quando enfocamos as condições de governança, no âmbito do poder local, desde já, rememoramos que tratamos da gestão do Estado comprometida com a democratização dos canais e processos decisórios, como forma de melhor gerir as 
relações clássicas entre Estado, mercado e sociedade. Entendemos que, a forma como os arranjos institucionais são estabelecidos, para governar essa relação, interferem na gestão dos direitos e, em especial, dos direitos sociais (SANTOS JÚNIOR; AZEVEDO; RIBEIRO, 2004).

O conceito de poder local carrega a proximidade com outras tipologias e contextualidades como: governo local, poder local, governança local, esfera pública (GOHN, 2003; RAMOS, 1997). Entendemos que este conceito é mais amplo que o conceito de governo local, visto que o poder local está também presente no interior do governo local, pode atuar em toda a amplitude da esfera pública (estatal e nãoestatal) e na produção das políticas públicas locais constituindo-se como força organizada e de influência no campo da ação coletiva, nos diversos aspectos da economia, da política e das relações sociais (GOHN, 2003; RAMOS, 1997).

No poder local, representado pela municipalidade no Brasil, a existência de uma relativa autonomia dos governos locais propicia o exercício mais dinâmico da democracia - movida pelos princípios da igualdade (em sua face redistributiva) e da universalidade. Mesmo que atravessada pelos seus próprios limites, pelas clivagens afetadas do neoliberalismo e pelos ditames imperiosos da globalização. Os municípios têm autonomia para alargamento das condições de um efetivo exercício dos direitos de cidadania (SANTOS JÚNIOR; AZEVEDO; RIBEIRO, 2004), como por exemplo, para estabelecer mecanismos mais democráticos de acesso às informações administrativas.

As discussões contemporâneas tratando da democracia das sociedades têm se aproximado do reconhecimento e legitimação do local, ou do poder local, na prática social e de seus atores. "O caminho, afirma, está na descentralização do governo, municipalização dos serviços e maior participação dos cidadãos." (RABELO, 2003, p. 29).

O uso da noção de poder local constitui um cenário mais fecundo para analisar a inserção da noção de controle social ${ }^{6}$ (GOHN, 2003). Segundo Souza (2002), paulatinamente, os governos locais vêm substituindo as funções do governo federal, principalmente quanto ao provisionamento de serviços sociais e também

\footnotetext{
${ }^{6}$ Controle social no âmbito das politicas sociais remete à possibilidade de ações, institucionalizadas ou não, por parte da sociedade civil organizada na gestão e controle das políticas públicas para que estas atendam e se orientem cada vez mais às demandas sociais e aos interesses dessa sociedade, que nas maioria das situações encontra-se em situação subalterna (CORREIA, 2002).
}

Inf. Inf., Londrina, v. 20, n. 1, p. 01 - 25, jan./abr. 2015. http:www.uel.br/revistas/informacao/ 
pelo formato como a descentralização e respectiva distribuição de poder. Salientando que essa substituição de funções é fruto das tensões entre o processo de descentralização instituído pela Constituinte, desde 1988, e as reações do executivo federal tendente à recentralização. Não relegando também a interferência e forte influência das reformas neoliberais que desde a sua emergência no Brasil regularmente têm forçado a diminuição do Estado e da oferta de serviços de natureza social.

Desde então, a temática gestão municipal vem assumindo a centralidade das discussões na formulação e execução das políticas públicas brasileiras. Esperava-se com a descentralização o fortalecimento financeiro e político dos estados, e principalmente dos municípios na relação com o governo federal. Porém, no modelo de descentralização instituído a consequência prática percebida tem sido a institucionalização de desigualdades na repartição dos recursos municipais (VELOSO, 2011).

A descentralização política ampliou o poder dos governadores e prefeitos (através das coalizões propiciadas pela redemocratização do país), mas por outro lado, também transferiu poder para segmentos da sociedade local, com adoção de políticas mais participativas (como a criação dos conselhos gestores). O contraditório nessa relação é que, segundo Santos (2001), as forças neoliberais e a própria atuação do capitalismo sempre se opuseram à redistribuição social facilitada pela dinâmica democrática e nessa correlação encontramos ações que se projetam para o fortalecimento da democracia participativa, promotora de maiores possibilidades de redistribuição social e antagonicamente, forças imperando no e junto ao Estado para minimizar essa potência no bojo da prática democrática.

Um dos entraves à descentralização refere-se à assimetria na disponibilidade de recursos entre os municípios gerando dificuldades de conciliação entre a descentralização fiscal e as desigualdades regionais. Uma das causas dessa assimetria decorre da visão estereotipada das desigualdades regionais, nos parecendo que: ainda faltam estudos e diagnósticos claros sobre as reais condições desses municípios. Nestes termos podemos pensar que os fatores que caracterizam as desigualdades entre municípios também não são reconhecidos conforme enfatizado por Veloso (2011, p. 17): "[...] ainda existe desconhecimento das reais necessidades dos gestores municipais", refletindo nas próprias dificuldades que os 
gestores federais têm na formulação de critérios mais adequados para direcionar as políticas públicas destinadas aos municípios.

A partir dessas referências históricas e breve articulação das categorias sociedade, informação e território constatamos que a discussão tornou-se estratégica dada a centralidade principalmente da informação na formação do homem e de seu território.

\section{REFERÊNCIAS}

ALBAGLI, Sarita; MACIEL, Maria Lucia. Informação e conhecimento na inovação e no desenvolvimento local. Ci. Inf., Brasília, v. 33, n. 3, p. 9-16, set./dez. 2004. Disponível em: <http://www.scielo.br/pdf/ci/v33n3/a02v33n3> . Acesso em: 18 abr. 2013.

ANDRADE, Maria Eugênia Albino; RIBEIRO, Carla Andréa. Governança informacional e políticas públicas de informação: pressupostos teóricos e interrelações. In: ENCONTRO NACIONAL DE PESQUISA EM CIÊNCIA DA INFORMAÇÃO, 5., 2003, Belo Horizonte. Anais... Belo Horizonte: Escola de Ciência da Informação da UFMG, 2003. 1 CD-ROM.

ARAÚJO, Eliany Alvarenga de. Informação, cidadania e sociedade no Brasil. Informação \& Sociedade: estudos, João Pessoa, v. 2, n. 1, 1992. 1 CD-ROM.

A construção social da informação: dinâmicas e contextos. Datagramazero, Rio de Janeiro, v. 2, n. 5, p.1-11, out. 2001. Disponível em: $<$ http://www.brapci.ufpr.br/ documento.php?dd0 $=0000001246 \& d d 1=56 f d 5>$. Acesso em: 3 nov. 2013.

BARRETO, Aldo de A. O rumor do conhecimento. São Paulo em Perspectiva, São Paulo, v. 12, n. 4, p. 69-77, 1998. Disponível em: <http://produtos.seade.gov.br/ produtos/spp/v12n04/v12n04_10.pdf>. Acesso em: 10 maio 2012.

. Os desafios da ciência da informação: entre o cristal e a chama.

Datagramazero, Rio de Janeiro, dez. 1999. Disponível em:

<http://www.dgz.org.br/dez99/Art_03.htm >. Acesso em: 3 nov. 2013.

. A questão da informação. São Paulo em Perspectiva, São Paulo, v. 8, n. 4, p.1-8, 1994. Disponível em: <http://produtos.seade.gov.br/produtos/spp/v08n04/v08n04_01.pdf>. Acesso em: 10 maio 2012.

BERGER, Peter L.; LUCKMANN, Thomas. A construção social da realidade: tratado de sociologia do conhecimento. 2. ed. Petrópolis: Vozes, 2002. 
BRASIL. Lei no 12. 527, de 18 de novembro de 2011. Regula o acesso a informações previsto no inciso XXXIII do art. $5^{\circ}$, no inciso II do $\S 3^{\circ}$ do art. 37 e no $\S$ $2^{\circ}$ do art. 216 da Constituição Federal; altera a Lei $n^{\circ}$ 8.112, de 11 de dezembro de 1990; revoga a Lei $n^{\circ} 11.111$, de 5 de maio de 2005, e dispositivos da Lei $n^{\circ}$ 8.159, de 8 de janeiro de 1991; e dá outras providências. Disponível em: <http://www.planalto.gov.br/ccivil_03/_ato2011-2014/2011/lei//12527.htm>. Acesso em: 2 jul. 2014.

. Lei no 7.724, de 16 de maio 2012. Regulamenta a Lei oㅜ 12.527, de 18 de novembro de 2011, que dispõe sobre o acesso a informações previsto no inciso XXXIII do caput do art. 5을 no inciso II do $\S 3^{\circ}$ do art. 37 e no $\S 2^{\circ}$ do art. 216 da Constituição. Disponível em: <http://www.planalto.gov.br/ccivil_03/_ato20112014/2012/decreto/D7724.htm>. Acesso em: 2 jul. 2014.

CASTELLS, Manuel. A sociedade em rede. 6. ed. São Paulo: Paz e Terra, 2002.

CASTRO, Ana Lúcia Siaines de. O valor da informação: um desafio permanente. Datagramazero, Rio de Janeiro, v. 3, n. 3, jun. 2002. Disponível em: <http://www.dgz.org.br/jun02/F_I_art.htm>. Acesso em: 5 out. 2013.

CORREIA, Maria Valeria Costa. Que controle social na política de assistência social. Serviço Social e Sociedade, São Paulo, ano 23, v. 1, n. 72, p.119-144, 2002.

FREIRE, Isa Maria. Acesso à informação e identidade cultural: entre o global e o local. Ci. Inf., Brasília, v. 35, n. 2, p. 58-67, maio/ago. 2006. Disponível em: $<$ http//:http:// revista.ibict.br/ciinf/index.php/ciinf/article/viewArticle/829/673>. Acesso em: 7 nov. 2013.

GARCÍA GÓMEZ, Francisco Javier; DÍAZ GRAU, Antonio. Desarrollo y gestión de la colección local en la biblioteca pública. 2. ed. Buenos Aires: Alfagrama, 2006.

GENTILLI, Victor. Democracia de massas: jornalismo e cidadania: estudo sobre as sociedades contemporâneas e o direito dos cidadãos à informação. Porto Alegre: EDIPUCRS, 2005. (Coleção Comunicação, 32).

GLEICK, James. A informação: uma história, uma teoria, uma enxurrada. São Paulo: Companhia das letras, 2013.

GOHN, Maria da Glória. Conselhos gestores e participação sociopolítica. 2. ed. São Paulo: Cortez, 2003. 120p. (Questões da nossa época, 84).

GONZÁLEZ DE GÓMEZ, Maria Nélida. O "socius" e o usuário de informação: a esfera da comunicação política. Revista Tempo Brasileiro, Rio de Janeiro, n. 86, p. 15-28, jul./set. 1986.

GONZÁLEZ DE GÓMEZ, Maria Nélida. Século XXI, a informação e o profissional da informação. In: SIMPÓSIO BRASIL-SUL DE INFORMAÇÃO, 1., 1996, Londrina.

Anais... Londrina: UEL, 1996. p. 281-300.

O caráter seletivo das ações de informação. Informare, Rio de Janeiro, v. 5, n. 2, p. 7-31, 2000. 
HJØRLAND, Birger. Library and information science: practice, theory, and philosophical basis. Information Processing \& Management, New York, v. 36, p. 501-531, 2000.

JARDIM, José Maria. Capacidade governativa, informação, e governo eletrônico. Datagramazero, Rio de Janeiro, v. 1, n. 5, out. 2000. Disponível em: <http://www.dgz.org.br/out00/Art_01.htm>. Acesso em: 5 out. 2013.

. Transparência e opacidade do Estado no Brasil: usos e desusos da informação governamental. Niterói: EdUFF, 1999. Disponível em: <http://www.uff.br/ppgci/ppgci_livros.htm>. Acesso em: 12 set. 2012.

LASTRES, Helena Maria Martins; ALBAGLI, Sarita (Org.). Informação e globalização na era do conhecimento. Rio de Janeiro: Campus, 1999. Disponível em: <http://www.uff.br/ppgci/ppgci_livros.htm>. Acesso em: 12 set. 2012.

LASTRES, Helena Maria Martins; AUN, Marta Pinheiro. Os novos requerimentos impostos às políticas nacionais de informação face à globalização e a conformação da Sociedade da Informação. In: CONGRESSO BRASILEIRO DE BIBLIOTECONOMIA DOÇUMENTAÇÃO E CIÊNCIA DA INFORMAÇÃO, 18., 1997, São Luiz. Anais... São Luiz: Associação de Bibliotecários do Maranhão, 1997. v. 1.

LOGAN, Robert K. Que é informação? A propagação da informação na biosfera, na simbolosfera, na tecnosfera e na econosfera. Rio de janeiro: Contraponto: Ed. PUCRIO, 2012.

MARTELETO, Regina Maria. Cultura, educação, distribuição social dos bens simbólicos e excedente informacional. Informare, Rio de Janeiro, v. 1, n. 2, p. 11-23, jul./dez. 1995.

NASCIMENTO, Denise Morado. A abordagem sócio-cultural da informação Informação \& Sociedade: estudos, João Pessoa, v. 16, n. 2, p. 21-34, jul./dez. 2006. Disponível em: <http://www.arq.ufmg.br/praxis/textos/morado_abordagem.pdf>. Acesso em: 10 ago. 2013.

NASCIMENTO, Lucileide Andrade de Lima do. Direito à informação e direitos sociais no contexto do capitalismo contemporâneo. 2007. Dissertação (Mestrado em Política Social) - Universidade Federal do Espírito Santo, Centro de Ciências Jurídicas e Econômicas, Vitória (ES), 2007.

OLIVEIRA, Vitória Peres de. Uma informação tácita. Datagramazero, Rio de Janeiro, v. 6, n. 3, jun. 2005. Disponível em:

<http://www.dgz.org.br/jun05/Art_04.htm>. Acesso em: 17 abr. 2014.

ORTEGA, Antônio César. Territórios deprimidos: desafios para as políticas de desenvolvimento rural. Campinas: Alínea; Uberlândia: Edufu, 2008. 
PEDRO, Rosa Maria Leite Ribeiro. A inclusão do outro na sociedade digital: reflexões sobre inclusão e alteridade. In: GONZÁLEZ DE GÓMEZ, Maria Nélida; LIMA, Clóvis Ricardo Montenegro (Org.). Informação e democracia: a reflexão contemporânea da ética e da política. Brasília: IBICT, 2011. p. 112-122.

PINTO, Álvaro Vieira. O conceito de tecnologia. 2. ed. Rio de Janeiro:Contraponto, 2005. 2 v.

QUÉAU, Philippe. La revolución de la información: en la búsqueda de un bien común. ACIMED, La Habana, v. 9, supl. 4, 2001. Disponível em:

$<$ http://scielo.sld.cu/scielo.php?pid=S102494352001000400015\&script=sci_arttext>. Acesso em: 13 maio 2012.

RABELO, Desirée Cripiano. Comunicação e mobilização na Agenda 21 local. Vitória: EDUFES: FACITEC, 2003.

RAMOS, Maria Helena Rauta. Poder local e acumulação capitalista na era da globalização. Praia Vermelha: estudos de política e teoria social, Rio de Janeiro, v. 1, n. 1, p.75-122, 1ํ sem. 1997.

ROBREDO, Jaime. Da ciência da informação revisitada aos sistemas humanos de informação. Brasília: Thesaurus: SSRR Informações, 2003.

SANTOS, Boaventura de Sousa. Seis razões para pensar. In: RODRIGUES, Leôncio Martins (Coord.). Por que pensar? Lua Nova, São Paulo, n. 54, p. 13-23, 2001. Disponível em: Disponível em: <http://www.scielo.br/pdf/ln/n54/a03n54.pdf>. Acesso em: 11 jan. 2014.

SANTOS JUNIOR, Orlando Alves dos; RIBEIRO, Luiz César de Queiroz; AZEVEDO, Sergio de. Democracia e gestão local: a experiência dos conselhos municipais no Brasil. In: SANTOS JUNIOR, Orlando Alves dos; AZEVEDO, Sergio de; RIBEIRO, Luiz César de Queiroz (Org.). Governança democrática e poder local: a experiência dos conselhos municipais no Brasil. Rio de Janeiro: FASE: Ed. Revan: Observatório IPPUR/UFRJ-FASE, 2004. p.11-56.

SILVA, Armando Malheiro da; RIBEIRO, Fernanda. Das "ciências" documentais à ciência da informação: ensaio epistemológico para um novo modelo curricular. Porto: Edições Afrontamento, 2002.

SILVEIRA, Henrique F. Rodrigues da. Um estudo do poder na sociedade da informação. Revista Ciência da Informação, Brasília, v. 29, n. 3, p. 79-90, set./dez. 2000. Disponível em: <http://www.scielo.br/pdf/ci/v29n3/a08v29n3>. Acesso em: 20 jan. 2014.

SOUZA, Celina. Governos e sociedades locais em contextos de desigualdades e de descentralização. Ciência \& Saúde Coletiva, Rio de Janeiro, v. 7, n. 3, p. 431-442, 2002. Disponível em: <http://www.scielo.br/pdf/csc/v7n3/13023.pdf>. Acesso em: 15 jan. 2014. 

território

SUAIDEN, Emir José; LEITE, Cecília. Dimensão social do conhecimento. In: TARAPANOFF, Kira (Org.). Inteligência, informação e conhecimento. Brasília: IBICT: Unesco, 2006. p. 99-114.

TATAGIBA, Luciana. Participação, cultura política e modelos de gestão: a democracia gerencial e suas ambivalências. 2003. Tese (Doutorado em Ciências Sociais) - Departamento de Ciência Política, Instituto de Filosofia e Ciências Humanas, Universidade Estadual de Campinas, Campinas, 2003.

TEIXEIRA, Elenaldo Celso. O local e o global: limites e desafios da participação cidadã. 3. ed. São Paulo: Cortez; Recife: EQUIP; Salvador: UFBA, 2002.

VELOSO, João Francisco Alves et al. Gestão municipal no Brasil: um retrato das prefeituras. Brasília: IPEA, 2011. Disponível em:

$<$ http://www.ipea.gov.br/portal/index. php?option=com content\&view=article\&id=10200 \&ltemid=2>. Acesso em: jan. 2012.

\section{Title}

The socio-spatial dimension of knowledge as an existencial human trait and its territory

\section{Abstract}

Introduction: It analyzes information as a crucial dimension in the process of social reproduction and therefore as a phenomenon that cannot be neglected in the analysis of society.

Objective: To position the use of information and knowledge as a social and highly collective practice, which establishes the relationship between individuals and between the individual and their environment (territory), based on the social paradigm of information.

Methodology: Develops a well-articulated theory from literary research, employing an interdisciplinary approach, which deals with the place of information and knowledge in society and the relationship between the categories of Social Control and Social Control of Information as a social mechanism for effective information governance, under an information system, to meet the informational and communicational needs of society.

Conclusions: Social Control applied to the field of information (Social Control of Information) is presented as a strategic mechanism to enable the effective management and socialization of local information based on the right to information; to channel and facilitate the participation of civil society under a system of information and to promote processes of information governance.

Keywords: Information and Society. Socialization of Knowledge. Territory and Information. Social Control and information. 

território

Dimensión socio-espacial del conocimiento como una marca existencial del hombre y su território

\section{Resumen}

Introducción: Analiza la información como una dimensión determinante en el proceso de reproducción social, por lo tanto, un fenómeno que no puede ser despreciado en el análisis de la sociedad.

Objetivo: Situar el uso de la información y del conocimiento como una práctica social y eminentemente colectiva, que se establece en la relación entre sujetos y entre el sujeto y su medio (territorio), con base en el paradigma social de la información.

Metodología: Desarrolla a partir de investigación bibliográfica articulación teórica, bajo un abordaje interdisciplinar, tratando del lugar de la información y del conocimiento en la sociedad y de la relación entre las categorías control social y control social de la información como mecanismo social para la efectivación del gobierno informacional bajo un régimen de información, para atención de la necesidad comunicacional y informacional de la sociedad. Conclusiones: La categoría control social aplicada al campo de la información (control social de la información) se presenta como un mecanismo estratégico para: viabilizar la efectiva gestión y socialización de la información local fundada en el derecho la información; y viabilizar canales de participación de la sociedad civil bajo un régimen de información promoviendo procesos de gobierno informacional.

Palabras-clave: Información y Sociedad. Socialización del Conocimiento. Território y Información. El control social y la información. 